\title{
Política social y teoría de la justicia. Los fundamentos del combate a la pobreza extrema en México
}

\author{
HeNio MilláN*
}

\begin{abstract}
The paper shows that after the adoption of the development manufacture exporting oriented model, the authorities found in Rawls' justice theory the foundations of social policy, particularly the one that refers to the struggle against extreme poverty. The reason of these finding is that only this foundation allows to make an active social policy compatible with the logic of the development model and with the economical policy of market liberalization. But in spite of the compatibility and possible synergies between both dimensions of the state task, the agenda of the struggle against poverty has several structural and institutional reform affairs to solve, which are absent in the global development strategy.
\end{abstract}

Keywords: extreme poverty, social policy, justice theory, growing.

\section{Resumen}

El artículo demuestra que tras la adopción del modelo de desarrollo orientado hacia la exportación manufacturera, las autoridades encontraron en la teoría de la justicia de Rawls el fundamento para la política social, señaladamente la que concierne al combate a la pobreza extrema. La razón de este hallazgo estriba en que sólo este fundamento permite hacer compatible una política social activa con la lógica del modelo de desarrollo y con la política económica de liberalización de los mercados. Pero a pesar de la compatibilidad y sinergias posibles entre ambas dimensiones del quehacer estatal, la agenda de la lucha contra la pobreza muestra asuntos pendientes de reforma estructural e institucional, ausentes en la estrategia global de desarrollo.

Palabras clave: pobreza extrema, política social, teoría de la justicia, crecimiento.

* El Colegio Mexiquense y Facultad Latinoamericana de Ciencias Sociales-México. Correo-e: hmillan@cmq.edu.mx 


\section{Introducción}

A diferencia de otras experiencias nacionales que han registrado políticas de ajuste estructural tendentes a la liberalización de sus economías, la mexicana no ha podido cristalizar su exitosa inserción en los mercados internacionales en una efectiva mejora del bienestar de su población. Antes bien, los resultados que arroja el desempeño económico y social después de quince años de reformas denuncian una expansión considerable de los niveles de pobreza, que representa una amenaza permanente sobre la legitimidad de la alternativa económica emprendida tras el agotamiento del modelo de sustitución de importaciones y después del fracaso de los últimos gobiernos, cuyas gestiones estuvieron marcadas por una decidida vocación por el intervencionismo estatal de viejo cuño.

Sin embargo, dicha amenaza ha servido para conjurar la idea de que el mercado, por sí mismo, es capaz de resolver los problemas de bienestar y equidad social por los que atraviesa una sociedad que se ha visto obligada a insertarse en un proceso de liberalización, en un contexto de fuertes desequilibrios en el orden social y económico. Hoy se arraiga cada vez más la creencia de que una 'tercera vía' es necesaria, a la luz de la contundencia de los resultados de un modelo que dista, después de quince años de reformas, de cumplir las promesas esgrimidas por sus más denodados impulsores. El problema, no obstante, queda sin resolver: las alternativas rivales han mostrado poca consistencia y la llamada política neoliberal resurge como un campeón golpeado, pero imbatible, al que sólo deben aplicarse algunas reparaciones menores para que siga en operación con un mínimo de legitimidad.

El gobierno mexicano no ha sido insensible a las voces que reclaman un cierto grado de intervencionismo estatal en la gestión social. El ejemplo más conspicuo lo representa la política de combate a la pobreza extrema, diseñada en reconocimiento de que la condición de marginalidad absoluta destierra cualquier posibilidad de que el mercado pueda extender sus beneficios hacia los grupos de personas más pobres; pero también de forma obligada, en virtud de que ese tipo de política es la más compatible con el modelo de desarrollo vigente. Éste opera como un referente inconmovible e inadaptable a circunstancias históricas y sociales específicas, al que debe subordinarse, mediante políticas ad hoc, la atención de problemas que escapan a la lógica del 
mercado, pero sin emprender regulaciones que alteren su funcionamiento.

El objetivo de este ensayo es demostrar que la inflexibilidad del modelo de desarrollo económico -impuesta en buena parte por las necesidades de acumulación y de inserción internacional- obliga a que el diseño y la operación de la política social contra la pobreza adopten una forma particular de gestión gubernamental, porque dicha forma resulta la única compatible con ese patrón de funcionamiento económico. Cualquier otra redundaría en desequilibrios macroeconómicos o en riesgos para el desempeño de los mercados, que alterarían el espíritu de las reformas estructurales y sus beneficios de largo plazo. En la primera sección, se describen los rasgos más sobresalientes del modelo de desarrollo, con la intención de señalar el carácter obligado de las políticas que le sirvieron de punto de arranque y de aquellas que son indispensables para que siga funcionando. La segunda expone el tema central de estas líneas: la compatibilidad entre el modelo y un combate a la pobreza inspirado en la teoría de la justicia de John Rawls. Por último, se examinan brevemente dos importantes fallas de esta estrategia social: la ineficacia del sistema educativo para coadyuvar al abatimiento de los índices de pobreza y la incapacidad de la economía para brindar oportunidades, en virtud de las restricciones al crecimiento.

\section{Rasgos centrales del modelo de desarrollo}

El modelo de desarrollo impone rigideces que dejan escasos márgenes para una política social activa y favorable a los pobres, sobre todo cuando ésta se despliega en un contexto de fuerte restricción presupuestal. Activado al mediar la década de los años ochenta, el nuevo modelo se fincó en la promoción de la exportación manufacturera, que desde entonces sustituyó al mercado interno como eje de la dinámica económica (Millán, 1998). Esta transformación demandó la instalación de un conjunto de premisas que, en última instancia, delimitan la capacidad de maniobra de la política social. Los rasgos de la transformación mexicana pueden resumirse de la siguiente manera:

\subsection{Crecimiento orientado hacia la exportación}

El agotamiento de la sustitución de importaciones y las mutaciones que ocurrieron en el escenario internacional durante los años 
ochenta cerraron los caminos para que México siguiera creciendo exclusivamente mediante impulsos del mercado interno.

En virtud del carácter desintegrado del aparato productivo, la inversión en México se ha revestido de un carácter autoderrotable, en el sentido de que sus efectos sobre la demanda efectiva y sobre la rentabilidad futura obligan a frenarla, una vez que ha arrancado el proceso de acumulación de capital. La alta dependencia de la importación de bienes de capital e intermedios introduce una distorsión estructural en la forma en que se desempeña la economía nacional. En condiciones normales, los efectos multiplicadores del gasto en inversión generan la cantidad exacta de ingreso para que pueda ser comprado el producto potencial asociado a ese volumen de inversión. Sin embargo, cuando ésta se realiza mediante bienes de capital de origen externo, esa demanda se fuga y la nueva capacidad instalada permanece ociosa, lo que afecta al incentivo para seguir invirtiendo.

El proceso de sustitución de importaciones revierte este carácter autoderrotable, en la medida en que posibilita que las fugas de la demanda sean compensadas por la expansión del mercado interno y, en consecuencia, que los rendimientos futuros de la inversión puedan mantenerse sin declinación (Millán, 1998). Esta mecánica revela el secreto del crecimiento alto y sostenido que registró, desde 1940 y durante tres décadas, la economía nacional. El problema reaparece cuando la sustitución de importaciones, tal y como ocurrió en México al iniciar la década de los setenta, se agota: la única alternativa viable para continuar el crecimiento es la exportación. En este sentido, la vocación exportadora del nuevo modelo de desarrollo no es una estrategia elegida, sino una reorientación obligada.

Desde otra perspectiva, los cambios que ocurrían en la economía internacional también introducían una presión adicional para que México adoptara transformaciones tendentes a una mayor integración en los flujos comerciales internacionales. Durante los años setenta, la evolución de la productividad laboral en las economías más industrializadas había registrado un notable rezago frente al comportamiento de los salarios (Fajnzylber, 1981). Éste no tardó en manifestarse en una drástica caída de la rentabilidad y en un estancamiento económico combinado con fuertes presiones inflacionarias. La respuesta fue la reconfiguración de los procesos productivos bajo una dimensión internacional, que en el fondo constituiría el embrión de la globalización. Se trataba de liberar mano de obra de los sectores, ramas y bienes 
de baja productividad, con el fin de canalizarla hacia la elaboración de artículos que desde entonces se visualizaban como los más dinámicos en el mercado internacional; por otra parte, la producción de esos sectores y ramas se trasladaba hacia algunas regiones industrializadas del tercer mundo.

La reestructuración implicaba, en los hechos, la puesta en marcha de una nueva división internacional del trabajo, en la que los países más desarrollados se especializaban en bienes de tecnología de punta y altamente intensivos en conocimiento, mientras la periferia industrializada se convertía en plataforma de exportación de los bienes abandonados por el mundo desarrollado.

A diferencia de la tradicional división entre bienes primarios y manufacturados, en la nueva división internacional del trabajo no había un espacio para todos. Para incrustarse en ella, los países subdesarrollados debían contar no sólo con mano de obra barata, sino con una base industrial relativamente diversificada y capaz de desempeñar procesos de producción más complejos, asociados principalmente con la manufactura de bienes durables. Aquellas naciones que aún fincaban sus esperanzas económicas en actividades primarias enfrentaban un oscuro panorama, porque la producción mundial había dejado de ser ventajosa para el Sur y se desplazaba abruptamente hacia el Norte. A este movimiento se sumaban la tendencia estructural hacia la sobreproducción y la consecuente depresión de los precios, así como la ola de innovaciones tecnológicas en la biotecnología y los nuevos materiales, que estaban destinadas a minar gravemente las ventajas derivadas de la dotación de recursos naturales.

Ante el agotamiento de este modelo de industrialización y en un mundo que anunciaba la liberalización de los flujos internacionales de comercio, las alternativas para México se reducían a una sola: exportar o naufragar en crisis más frecuentes y más severas.

\subsection{La apertura comercial}

Al abrir la economía a la competencia externa, las autoridades se proponían reorientar el aparato productivo hacia el exterior. El desmantelamiento de las barreras no arancelarias y el sucesivo debilitamiento de la estructura tarifaria aportaron a estas intenciones un doble beneficio: por un lado, la reducción de la protección efectiva debía traducirse en la reducción del sesgo exportador y, por esta vía, en un aumento de la rentabilidad relativa del 
mercado internacional sobre la demanda interna. Por el otro, la amenaza de una competencia acicateada por un mayor volumen de importaciones debía obligar a los productores nacionales a impulsar mejoras sustanciales y continuas en la competitividad de los bienes y servicios.

\subsection{La reforma económica del Estado}

La nacionalización del sistema bancario nacional había mostrado los límites políticos de la expansión del Estado. Sobre ellos también se montaba la necesidad de trastocar la injerencia estatal en los procesos económicos, para transitar hacia esquemas de mayor protagonismo de la iniciativa individual. La centralidad que el nuevo modelo suministra a la competitividad demanda un sistema de precios que reflejen los costos de oportunidad, a fin de que la asignación de recursos sea eficiente. Las regulaciones excesivas, los precios administrados y los subsidios introducen distorsiones que alteran esa asignación e inhiben la competitividad potencial de la economía.

Por esta razón, el tránsito hacia un patrón de crecimiento fincado en la exportación manufacturera debió ser acompañado con el desmantelamiento de una parte sustancial del aparato económico del Estado, así como con un proceso de liberalización que aminoró drásticamente la amplia gama de regulaciones que hasta entonces habían flagelado la economía mexicana.

La lucha por balancear las finanzas públicas tuvo también un efecto permanente sobre las dimensiones de ese aparato. Una inflación alta y permanente es incompatible con la competitividad, en la medida en que revierte los efectos positivos de una mayor eficiencia productiva y tiende a reconducir la oferta de bienes transables hacia el mercado interno. Por tal razón, su combate se convirtió en un punto ineludible de la estrategia exportadora. Para abatirla, las autoridades debieron escoltar su estrategia contra los aspectos inerciales de la inflación con una política de ingresos que exigía importantes ajustes en los presupuestos públicos y que terminó por redimensionar la plantilla burocrática. En adelante, el cuidado de los equilibrios fiscales se convertiría en un sello indeleble del quehacer hacendario mexicano. 


\section{La compatibilidad de la política social}

Al ubicar a la competitividad en el centro de la estrategia económica, se azolvan las vías optativas para desplegar una política social activa contra la pobreza, que sea compatible con el modelo de desarrollo y estrategia económica que lo acompañan. La necesidad de conservar la disciplina en las finanzas públicas anula la posibilidad de impulsar el empleo y la demanda agregada por vías fiscales y monetaria. El gasto público ya no puede asumir su tradicional papel de acicate del mercado interno, la inversión y del empleo, porque los déficit fiscales acarrean desequilibrios que, a la larga, generan presiones en la balanza de pagos, en el nivel de precios y las tasas de interés, que acaban por inducir caídas drásticas en el nivel de actividad. En este sentido, el volumen de empleo queda sujeto a la dinámica de la inversión privada, y ésta, al desempeño del complejo exportador y de sus vinculaciones con el resto del aparato productivo.

En virtud de que los procesos inflacionarios representan una seria amenaza contra la competitividad, los salarios reales enfrentan invariablemente el tope de la productividad laboral. Cuando ésta crece, pero aún se encuentra en niveles inferiores a los internacionales, los salarios reales tienden a rezagarse hasta que las productividades se emparejan. En un contexto de competencia externa, las empresas nacionales que exhiben una desventaja en la productividad del trabajo tienen tres opciones para seguir en el mercado: disminución de las utilidades unitarias, reducción de costos fijos medios o debilitamiento de los salarios. La disminución de las utilidades se antoja poco probable, en la medida en que constituyen una de las principales fuentes para la reorganización productiva y la innovación tecnológica a las que se ven impelidas por la apertura externa. Por su parte, en la medida en que el mercado interno se encoge al calor de la apertura externa, los costos fijos unitarios son difíciles de reducir. Estos elementos dejan a los salarios como una variable de contrapeso para encarar la discrepancia entre la productividad doméstica y la externa.

Los subsidios generalizados al consumo, que tradicionalmente operaban como un paliativo importante a las condiciones de pobreza extrema, resultan incompatibles con la política económica de corto plazo, por el peso oneroso que representan para las finanzas públicas, y con la estrategia económica, a causa de 
sus efectos nocivos sobre la asignación de recursos y la competitividad.

Estas restricciones dibujan un espacio muy preciso para la política social, en la medida en que demarcan nítidamente los límites en los que debe encuadrarse el combate a la pobreza extrema. El esfuerzo emprendido por el gobierno, especialmente a partir de la administración de Ernesto Zedillo, representa la forma de desplegar una política contra la pobreza que sea compatible con la política económica en vigor y con el modelo de desarrollo en marcha.

La visión liberal que la anima puede ser identificada, sin escrúpulo alguno, con las aportaciones de John Rawls a la teoría de la justicia, entendida como equidad. La perspectiva liberal promete destrabar las potencialidades del ser humano, a la luz de la premisa de que los individuos -autointeresados y que operan en un marco de libertad bajo un mínimo de normas que ellos mismos se dan- son originalmente iguales, en cuanto a sus capacidades y motivaciones se refiere. La guerra perpetua del estado de naturaleza que describe Hobbes sólo puede ser entendida por la equiparación de las fuerzas de los individuos en pugna; la postulación cartesiana en torno a la equidad en la distribución de la razón y la propia Constitución de los Estados Unidos apuntan a que la igualdad es el cimiento en el que reposa el arreglo social bajo principios liberales. La diferenciación social no puede ser, entonces, más que el fruto del esfuerzo personal; las limitaciones de todo tipo -temporales, biológicas, etcétera- vuelven materialmente imposible que las distancias económicas y sociales entre individuos libres sean tan grandes como para arrojar una sociedad ostensiblemente desigual.

Las inquietudes de Rawls emergen cuando el liberalismo pretende normar una sociedad signada por la desigualdad. Desde un punto de vista sociológico, la consecuencia es la acentuación de las disparidades e injusticias sociales, más que una tendencia hacia la convergencia en los niveles de bienestar. Desde un punto de vista ético -que es el que interesa a Rawls-, el problema deriva de un exceso de desigualdad injustificable, cuya corrección demanda una acción colectiva a favor de los menos aventajados. En esencia, el problema consiste en determinar cuándo y qué tanta desigualdad se justifica.

La respuesta de Rawls (1995) se finca en las teorías del pacto: individuos racionales, pero sujetos a un velo de ignorancia 
que garantiza su imparcialidad, y acuerdan dos principios de justicia que deben ser aceptables para todos:

I. Cada persona ha de tener un derecho igual al más extenso sistema total de libertades básicas compatible con un sistema similar de libertad para todos;

II. Las desigualdades económicas y sociales han de ser estructuradas de manera que sean para:

a) mayor beneficio de los menos aventajados, de acuerdo con el principio de ahorro justo, y

b) unidas a los cargos y las funciones asequibles a todos, en condiciones de justa igualdad de oportunidades (Rawls, 1995: 280).

El primero de estos dos se conoce como el principio de igual libertad; el segundo contiene, en su apartado (a), el principio de diferencia y la restricción ahorro, y en (b), el correspondiente al de igualdad de oportunidades. Así, mientras aquél busca que las libertades básicas se distribuyan en partes iguales entre los individuos, el segundo pretende determinar cuándo y qué tanta desigualdad puede ser justificada.

Las libertades básicas que invoca el principio de igual libertad son: la libertad política, entendida como el derecho a votar y a ser elegido para ocupar puestos públicos; la libertad de expresión y de reunión; la libertad de conciencia y de pensamiento; la libertad de la persona, que consiste en el derecho a no ser oprimido físicamente o psicológicamente, ni a sufrir atentados contra la integridad; el derecho a la propiedad personal y la libertad frente a las detenciones arbitrarias (Rawls, 1995: 68). El acceso igualitario a este sistema de libertades sólo puede ser restringido si de tal constreñimiento resulta una ampliación de las libertades que lo conforman; es decir, si opera a favor de la propia libertad.

El segundo principio amerita algunas aclaraciones. En primer lugar, aplica a la distribución de la riqueza y del ingreso, así como a los puestos de autoridad y de responsabilidad. Sin embargo, tal enfoque constituye una primera aproximación, porque en la concepción rawlsiana estas dimensiones de la desigualdad son producto de la forma en que se distribuyen los bienes sociales primarios: aquellos que las personas siempre quisieran tener más. "Son derechos, libertades, oportunidades y poderes, así como ingresos y riquezas" que les permiten aumentar sus probabilidades de éxito para realizar su plan racional de vida. Una dotación más generosa robustece las expectativas de los individuos de desarrollarse conforme a ese plan.

En segundo lugar, el postulado del principio de la diferencia contiene un elemento que podemos llamar esencial, pero que 
se encuentra condicionado a varias restricciones. La idea central de este componente consiste en disponer que las desigualdades sólo tienen una justificación ética cuando se aprovechan para beneficiar a los menos aventajados. Más precisamente: cuando estas desigualdades son necesarias para maximizar las expectativas de los peor situados en la escala social. Esta proposición es un caso especial del principio de distribución equitativa, el cual prescribe un reparto igual de los bienes primarios sociales, si y sólo si no existe una distribución alternativa que redunde en un beneficio mayor de los menos aventajados. Si la sociedad dispone de una opción más provechosa para ese núcleo de la población, la desigualdad está, en principio, justificada (Rawls, 1995: 281).

Sin embargo, para que tal justificación sea cabal es preciso que se cumpla con dos restricciones: el principio de justo ahorro y el de igualdad de oportunidades. La primera impone, por un lado, la obligación moral de transmitir a las siguientes generaciones una proporción de ahorro similar a la que recibieron de sus antecesoras. La finalidad no es el crecimiento económico, que implica la postergación del consumo presente en aras de un consumo futuro mayor, sino la preservación de una sociedad fincada en instituciones que, a su vez, encarnen y mantengan vivos los principios de justicia en el curso del tiempo:

Es también característico de la doctrina contractual el definir una sociedad justa como objetivo del curso de acumulación [...] El principio de ahorro justo puede contemplarse como un acuerdo entre las generaciones para cumplir su parte en el trabajo de realizar y proteger una sociedad justa (Rawls, 1995: 271).

Por otro lado, el principio de ahorro rechaza la idea de que las generaciones actuales deben ser sacrificadas con una carga excesiva, con el fin de que las posteriores puedan gozar de mejores condiciones materiales de existencia. El compromiso entre las generaciones apunta fundamentalmente hacia la preservación de la igualdad en las libertades básicas; sólo en ese sentido cobra significado el progreso económico y, en consecuencia, el imperativo moral de ahorrar para las generaciones futuras.

Por su parte, la restricción que impone el principio de igualdad de oportunidades postula, primero, que la desigualdad es justificada si proviene de diferencias en capacidades y no de un acceso discriminatorio a puestos y posiciones que posibilitan un lugar privilegiado en la sociedad; y segundo, que tal desigualdad sólo puede ser aprovechada a favor de los menos aventajados, si proviene de esas circunstancias igualitarias, en cuanto a las opor- 
tunidades se refiere. Sin embargo, visto aisladamente, en el principio de igualdad de oportunidades también opera una lógica similar a la del principio de igual libertad: sólo puede aceptar restricciones, si éstas conllevan una ampliación de las oportunidades, especialmente para los que menos tienen. La contradicción que este último postulado representa para la prioridad de la igualdad de las oportunidades sobre el principio de diferencia, revela que ésta no es absoluta, sino que está determinada por circunstancias específicas:

Para ser congruentes con la prioridad de la igualdad de oportunidades sobre el principio de diferencia, no basta alegar, como parecen hacerlo Burke y Hegel, que toda la sociedad, incluyendo a los menos favorecidos, se benefician de ciertas restricciones a la igualdad de oportunidades. También es necesario decir que el intento de eliminar estas desigualdades interferiría con el sistema social y las operaciones de la economía, de modo que a largo plazo las oportunidades de los menos aventajados estarían aún más restringidas. La prioridad de la igualdad de oportunidades, como en el caso similar de la prioridad de la libertad, significa que debemos recurrir a las oportunidades dadas a aquellos con menores probabilidades. Debemos mantener que, de este modo, se les abre un campo más amplio de alternativas más deseables de lo que hubiese sido en otro caso. La pretensión, menos definida, de que toda la sociedad se beneficia, sólo basta cuando las circunstancias justifican el abandonar el orden lexicográfico y pasar a un equilibrio intuitivo de igualdad de oportunidades contra beneficios sociales y económicos. Estas circunstancias pueden exigirnos -o no- que abandonemos, asimismo, el ordenamiento lexicográfico de los principios de justicia. Los dos ordenamientos pueden entrar en juego en distintos momentos (Rawls, 1995: 279).

La extensión de la cita anterior es justificada, porque el argumento es muy elocuente para nuestros propósitos de encontrar un referente para la política social en México. La invocación de la igualdad de oportunidades pretende desterrar una visión meritocrática, fincada en la idea de que es preciso mantener un grupo social privilegiado, cuyos miembros conforman el contingente de personas reclutables para los puestos de dirección de la sociedad. En su lugar, Rawls propone una igualdad de oportunidades regida por las capacidades, tanto para la educación y la cultura, como para los trabajos y empleos (Rawls, 1995: 260). La combinación disminuye la posibilidad de que las diferencias entre los grupos sociales se ensanchen. En el primer orden social, el grupo privilegiado tiene a su alcance la mejor educación y los mejores accesos, mientras ambas dimensiones del desarrollo individual son restringidas en función de una prosperidad común; en el segundo caso, las oportunidades se abren para todos, con indepen- 
dencia de su posición social, pero sujetos a la condición de comprobar capacidades y esfuerzos similares. En este sentido, la primera perspectiva constituye una interpretación aristocrática de los principios de justicia, mientras en la otra es la visión democrática la que prevalece. Sólo esta última representa fielmente los propósitos de una sociedad justa.

Para nuestros propósitos de ubicar la política social contra la pobreza en el modelo de desarrollo, la lectura de Rawls aporta un número significativo de elementos que pueden relacionarse con la lógica económica y social que anima la acción pública desde mediados de los años ochenta. Se trata de identificar las piezas del rompecabezas rawlsiano con los componentes esenciales que definen ese modelo y, una vez realizado tal ejercicio, armar un esquema de funcionamiento para aquella política social.

En esta dirección, nuestra propuesta es que el principio de igual libertad y el de igualdad de oportunidades pueden ser identificados con el propósito de afianzar el libre mercado como mecanismo privilegiado de asignación de los recursos. Aunque el mismo Rawls nos advierte que la libertad de mercado no es inherente a la propiedad privada de los medios de producción, estos dos principios concuerdan con el mercado libre (Rawls, 1995: 254-255), porque éste permite la libre elección de carreras y ocupaciones, la descentralización del ejercicio del poder económico y porque las empresas y consumidores pueden tomar sus decisiones de manera independiente. Cuando los mercados no son verdaderamente competitivos, estas libertades se ven amenazadas por la interferencia de poderes económicos o extraeconómicos.

Por otro lado, el principio de ahorro remite directamente al crecimiento económico, por lo menos la parte que estipula la necesidad de transferir a las siguientes generaciones una proporción del ingreso similar a la recibida, porque el ahorro es la fuente de financiamiento de la acumulación de capital, y por este conducto, del dinamismo económico.

Por último, el uso de las desigualdades a favor de los menos aventajados puede identificarse como la política social de combate a la pobreza, especialmente la que se reproduce en condiciones extremas. Este tipo de pobreza se caracteriza por su carácter absoluto, que impide que los individuos en esta situación adquieran las capacidades suficientes para desarrollar un proyecto de vida que ellos consideran digno (Sen, 2000). La carencia de capacidades minimiza sus expectativas para desarrollar ese proyecto de vida, sobre todo cuando dichas capacidades son determinantes 
del éxito individual en un mercado signado por la competencia. En este sentido, la comparación con las imágenes rawlsianas es plausible, por lo menos en tres dimensiones: el proyecto de vida, las expectativas para su realización en una economía competitiva de libre mercado y el papel de los menos aventajados en la justificación de la distribución de los bienes primarios, en los que se cimientan esas expectativas.

En la visión de Rawls, todos los hombres desean desplegar un proyecto de vida, cuyas expectativas de realización descansan en una dotación determinada de bienes sociales primarios: derechos, libertades, oportunidades y poderes, así como ingresos y riquezas. Dado un marco jurídico que garantiza las libertades básicas, éstos dependen de la capacidad de insertarse en la dinámica social, y ésta, de la dotación de activos físicos, financieros y humanos, cuya carencia es distintiva de los más pobres. Si se asume que los pobres extremos viven en condiciones no sólo de miseria sino de marginalidad, pueden ser caracterizados por una insuficiencia de esos bienes primarios: la exclusión social impide el ejercicio de los derechos y libertades; la carencia de capacidades (capital humano) y la parquedad de los activos físicos y financieros obstaculizan el acceso a las oportunidades y a la generación de ingresos, tanto por la vía laboral como por la mercantil. En este sentido, de acuerdo con los criterios de la justicia como imparcialidad, sus expectativas anuncian la imposibilidad de remontar no sólo el rezago social y humano que padecen, sino también de abandonar sus condiciones de pobreza extrema. La prescripción política es clara: si se pretende maximizar las expectativas de esos núcleos de población, la acción pública debe encaminarse a la dotación de los bienes primarios sociales. Pero en la práctica, tal dotación se debe circunscribir, por lo menos en las primeras etapas del proceso, al desarrollo de capacidades y de habilidades para los más pobres y, en menor medida, al fomento de capitales productivos embrionarios.

Entonces, en un escenario de mercado libre, una política hacia los menos aventajados consiste, esencialmente, en habilitarlos para competir. Sin una dotación adecuada de capital (físico y humano) sus posibilidades de librar con éxito las batallas cotidianas de la competencia son prácticamente nulas, en virtud de que en ese espacio los ingresos son una función de las productividades marginales de los factores, cuyo comportamiento describe apropiadamente la demanda que esos factores enfrentan, especialmente cuando se satisfacen los supuestos en los que descansa 
el modelo de competencia perfecta. La inserción en el mercado facilita el acceso a derechos vinculados con la seguridad social y con otros mecanismos de solidaridad, al tiempo que acerca a los individuos a las fuentes de oportunidades y los sitúa en posición de exigir con más fuerza el respeto a una amplia gama de libertades. El desarrollo de las capacidades se vuelve determinante de las expectativas de los menos aventajados, especialmente cuando éstos están caracterizados no sólo por la pobreza extrema, sino por la marginalidad, como sucede en el caso mexicano. Sin ellas, las posibilidades de incorporación de los más pobres a la dinámica del mercado no sólo se debilitan, sino que cuando las circunstancias la permiten, su escasa competitividad ante agentes económicos y sociales más habilitados se encarga de regresarlos a su situación original. El proceso está representado en el esquema I.

\section{Esquema I}

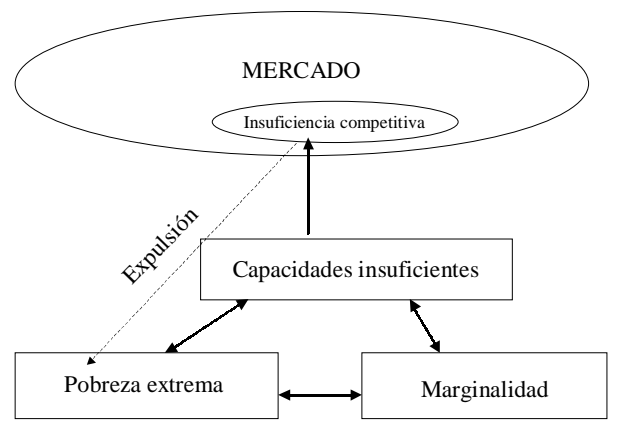

Al amparo de la lógica rawlsiana, una política social de combate a la pobreza extrema (los menos aventajados) orientada hacia las capacidades y eventualmente complementada con la dotación de capitales seminales, tiene como destino final el mercado. Los mecanismos, en principio, pueden ser dos: el mercado laboral y el desarrollo de vocaciones empresariales, inhibidas, pero presentes en una gama muy amplia de pobres extremos, contra lo que generalmente se suele pensar. La competencia implícita en el nuevo modelo de desarrollo obliga a que ambas deban pasar, antes de llegar al mercado, por el despliegue de un grupo de capacidades, si se quiere sortear con éxito las vicisitudes mercantiles, tanto en el ámbito laboral como en el que se desarrollan las transacciones de bienes y servicios. Pero también la política social inspirada en Rawls denuncia que la mecánica del mercado, por sí 
misma, es incapaz de suministrar tales atributos al grupo de los menos aventajados. En este sentido, la acción del Estado debe encaminarse a suplir esta 'falla de mercado': habilitar a los más pobres para que sean capaces de incrustarse en el mercado y para sobrevivir a la competencia asociada al libre juego de la oferta y de la demanda. El resultado esperado es una reducción de la pobreza extrema y, consecuentemente, la maximización de las expectativas de grupo social. Esta lógica se puede apreciar en el esquema II.

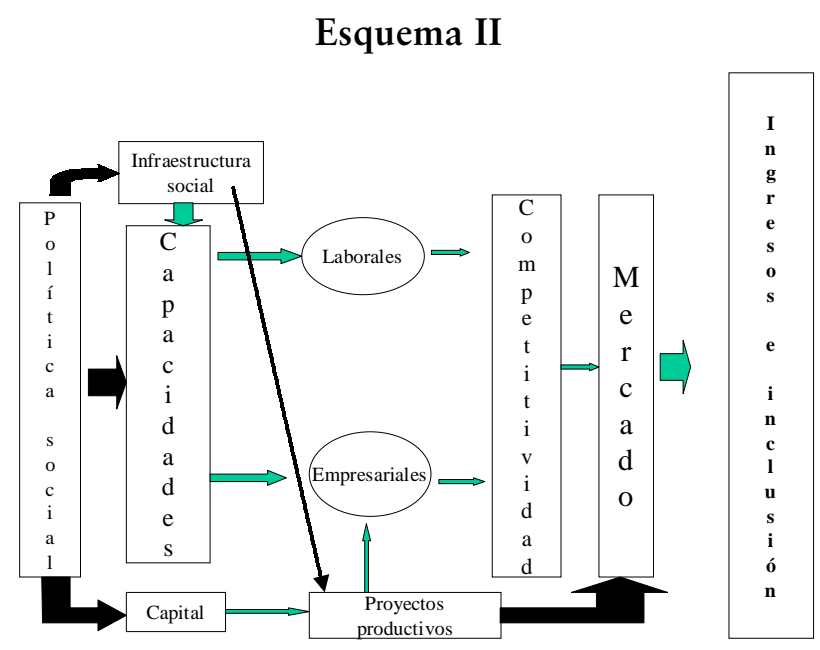

En este esquema se muestra el lugar central que en la política contra la pobreza extrema ocupa el suministro de capacidades. Desde la perspectiva rawlsiana, esta centralidad deriva de que tanto el ejercicio de los derechos y libertades como los ingresos y el acceso a la riqueza dependen crucialmente de esas capacidades, en la medida en que son una condición ineludible tanto para el desarrollo de los atributos que configuran la ciudadanía como para el impulso de la productividad y de la competitividad, es decir, en última instancia, la gama de bienes primarios sociales que rigen las expectativas de los más pobres.

Adaptada por las autoridades mexicanas, especialmente a partir de 1997 cuando la focalización se convirtió en el nuevo consenso en torno a la asignación de recursos fiscales, esta visión de la política social contra la pobreza adoptó tres vertientes fundamentales: la formación de capital humano, el desarrollo de proyectos productivos y la dotación de infraestructura social básica (Poder Ejecutivo, 1998, 1999, 2000, 2001). La lógica que las 
combina está representada por el esquema anterior y puede sintetizarse de la siguiente manera:

- El suministro de capacidades a los pobres extremos (los menos aventajados) tiene como finalidad aumentar la competitividad de estos núcleos sociales, en la medida en que tal propiedad es indispensable para incurrir en el mercado y permanecer en él, cuando este mecanismo se distingue por ser libre y competitivo. En esencia, consiste en aquellos elementos que son necesarios para desempeñarse adecuadamente en el mundo escolar y productivo: educación, salud y alimentación. El despliegue de las capacidades permite desarrollar habilidades laborales y empresariales. Las primeras son diseñadas para preparar a los individuos para emplearse en el mercado de trabajo; las segundas, para estimular vocaciones empresariales soterradas, así como para adquirir un mínimo de conocimientos necesarios para el desempeño en actividades mercantiles, como la detección y aprovechamiento de las oportunidades de negocios, los elementos aritméticos indispensables para realizar tareas contables rudimentarias y los aspectos legales en los que, eventualmente, puede verse involucrado el quehacer empresarial.

- El estímulo de la vocación empresarial debe ser complementado con la dotación de un capital embrionario, el cual puede asumir la forma de microcréditos a individuos o de préstamos a grupos sociales que aprovechan el capital social latente, tejido con las relaciones de solidaridad de una comunidad determinada. Su función es avituallar a los beneficiarios de la inversión necesaria para emprender proyectos productivos capaces de suministrar un flujo de ingresos más o menos estables y equivalentes a empleos relativamente bien remunerados, en virtud de los límites que el crecimiento y la propia competitividad del sistema económico suelen imponer a la capacidad de absorción de empleo de la economía.

- La infraestructura social básica es un complemento indispensable para el desarrollo tanto de las capacidades como de los proyectos productivos. La mejor forma de observar su sentido complementario es imaginar el despliegue de la política a favor de las capacidades y de los proyectos productivos sin su ayuda: la formación educativa es insuficiente si no se cuentan con planteles adecuados y accesibles o con una red suficiente de servicio eléctrico que permita el 
cumplimiento de los deberes académicos extraescolares. Sin una vivienda digna, el estudio no sólo se dificulta, sino que la salud se ve constantemente amenazada, sobre todo cuando el hogar carece de drenaje, agua potable, letrinas y alcantarillado. Asimismo, sin caminos rurales propicios se imposibilita el abasto suficiente y relativamente barato de alimentos y nutrientes, indispensables para el desempeño escolar y laboral. Todas estas carencias, en suma, afectan negativamente la formación de capacidades y, por lo tanto, la efectividad de esa vía de lucha contra la pobreza extrema. - Pero también la deficiencia en los servicios que presta la infraestructura social básica asesta efectos perniciosos sobre la actividad productiva: sin caminos no puede ser adecuada y oportunamente comercializada la producción de bienes y servicios, ni el acceso a insumos, eficiente. Su precio relativo corre el riesgo de sufrir mermas importantes que acaban por deprimir el ingreso de aquellos que se beneficiaron de la política social. Sin electrificación y abasto suficiente de agua, los costos se elevan y la jornada de trabajo puede verse seriamente limitada. Estos argumentos cobran su verdadero significado en un contexto en el que la producción de los más pobres debe librar la batalla de la competitividad en mercados más disputados, en virtud de la apertura comercial y, eventualmente, de una demanda interna que no crece al ritmo suficiente para absorber todos los frutos de la actividad económica.

Los componentes y la lógica de la política de combate a la pobreza extrema suponen que la competitividad y el libre mercado son elementos inamovibles, referentes de la acción pública. La razón estriba en el papel que ambas dimensiones asumen en el proyecto, más general, de funcionamiento económico y social. Como se ha explicado, la liberalización de las prácticas económicas configura la respuesta tanto al agotamiento del modelo de industrialización orientado hacia la sustitución de importaciones, como a la necesidad de insertarse en una economía internacional signada por la globalización de los procesos económicos, porque la operación del mercado sin trabas significativas es una condición necesaria -aunque insuficiente- para que la asignación de recursos se efectúe eficientemente. Sin tal atributo, la exportación y la inserción a los flujos internacionales no pueden ser sostenidas como proyecto de largo plazo. En esa dirección, la política social debe tener al mercado no sólo 
como destino, sino como referente: en la medida en que la supervivencia y el bienestar no pueden soslayar indefinidamente los mecanismos mercantiles, porque de ellos depende la viabilidad histórica de la nación, y especialmente, la del modelo económico, su esencia no es otra que la de preparar para el mercado a quienes, por su carencia o insuficiencia de capacidades, no están en condiciones de competir. Su naturaleza es, entonces, fundamentalmente temporal y subsidiaria: se ayuda al desvalido hasta que esté en condiciones de valerse por sí mismo. Y esto ocurre cuando desarrollan capacidades para permanecer en un universo económica y socialmente competitivo.

Pero también el mercado y el modelo de desarrollo representan las coordenadas en las que la política social y el combate a la pobreza extrema pueden moverse, al tiempo que señalan el lugar que ambas deben ocupar en la jerarquía de la gestión pública global. Su ubicación también puede ser detectada mediante la priorización lexicográfica que nos propone Rawls.

Cuando se aplica el orden de Rawls a la lógica del modelo de desarrollo y al espacio que en ella ocupan las distintas vertientes de la política pública, la prioridad del primer principio -igualdad de la libertad- muestra la preeminencia del libre mercado sobre todas las acciones del Estado a favor de los menos favorecidos. Especialmente, exhibe la centralidad que asume el mercado de bienes (y servicios) en la asignación de recursos, porque de su libre funcionamiento depende la eficiencia y el bienestar del conjunto social. En términos más prácticos, significa que la política contra la pobreza puede ser desplegada siempre y cuando no altere el libre funcionamiento de ese mercado, $y$, particularmente, que no distorsione el sistema de precios relativos, en la medida en que su estructura es la responsable de emitir las señales para distribuir los recursos de la sociedad entre actividades económicas y/o entre fines alternativos. Una visión como esta elimina del inventario de instrumentos de política los subsidios generalizados al consumo y a la producción, los controles de precios, la producción pública con criterios extrapecunarios; el suministro de créditos selectivos a tasas preferenciales, las políticas arancelarias y no arancelarias de protección al mercado interno, entre otros. Todos ellos ejemplifican los instrumentos que fueron privilegiados mientras prevaleció el carácter cerrado de la economía nacional, asociado con la industrialización sustitutiva y con la presencia estatal en el proceso de desarrollo. 
La igualdad de las oportunidades refiere a los otros mercados que, junto con el de bienes, complementan el enfoque macro de la economía: el mercado de factores y el de activos. De ambos depende una parte significativa de los ingresos familiares, y por ello, son determinantes incomparables de una las dimensiones más importantes del bienestar social. Recuérdese que la idea fundamental de Rawls es que el acceso a los puestos y ocupaciones debe estar desligado de la posición social en la que se encuentre los individuos, aunque tal posición pueda ser el resultado de la función involucrada en el ejercicio de los mismos. Dichos puestos deben ser para los más aptos, es decir: para aquellos que demuestren mayor capacidad para desempeñarlos. Por ello, Rawls insiste en que la igualdad de oportunidades se reduce, en esencia, al igual acceso a la educación y, en general, a la posibilidad de desarrollar conocimientos y aptitudes en igualdad de condiciones. Cuando estos requisitos se cumplen, los individuos deben competir por los puestos, de forma que su asignación sea el fruto de esa competencia. De lo contrario, no sólo se corre el riesgo de arraigar una injusticia moral, sino de afectar la competitividad global de la economía, con efectos nocivos para el desarrollo: los arreglos sociales dejarían de premiar el esfuerzo personal -premisa en la que se sustenta la diferenciación social en todas las visiones liberales- e introducirían sesgos en la estructura de incentivos que conducirían al desperdicio de los beneficios esperados de la iniciativa individual.

Por tal motivo, no es descabellado identificar la prioridad del principio de igualdad de oportunidades sobre el principio de diferencia con la supremacía de la competitividad sobre la política social de combate a la pobreza extrema. Al combinarse con el libre mercado, la prescripción rawlsiana en torno a la igualdad de oportunidades toma forma cuando se aplica a la política pública que acompaña al nuevo modelo de desarrollo: los agentes sociales deben competir en el mercado de bienes y en el de factores, porque sin competencia no puede emerger la competitividad.

Lo mismo puede decirse del capital o de la tierra. La teoría económica distingue claramente entre la propiedad de los factores y los servicios que éstos proporcionan. En este mercado se intercambian estos servicios, de manera que sus remuneraciones representan los precios determinados por la interacción de la oferta y de la demanda. En el caso del capital -o de la tierra- este servicio puede ser prestado por un propietario dedicado a actividades 
empresariales o por el mercado de activos financieros, en virtud de que ambos tenderán a suministrar un rendimiento similar, es decir, en ambos casos, la ganancia de la empresa, una vez descontado el costo de capital, no será otra cosa que la retribución por el uso de otro factor productivo: la gestión empresarial. En esencia, al usuario de este servicio le será indistinto aplicar su propio capital a las actividades productivas o solicitarlo en el mercado financiero. Situación que sustenta la aplicación del principio de igualdad de oportunidades: aun cuando los mercados de activos -y de crédito- operan libremente, sin barreras a la entrada de oferentes o demandantes. No obstante, la desigualdad en la distribución de la riqueza puede persistir sin desmedro de ese principio, en razón de que quien aspira a desempeñarse como empresario, pero carece del capital necesario, goza de las mismas oportunidades que aquellos que ostentan la propiedad de este factor productivo.

El principio de igualdad de oportunidades busca contrarrestar las ventajas y desventajas que emergen de las condiciones socioeconómicas, y que inciden en el acceso a puestos y ocupaciones determinados, porque representa un complemento indispensable de la competencia que, en términos justos, los individuos que aspiran a ellos deben ejercitar. Si las habilidades de los individuos se equiparan porque todos tuvieron la misma oportunidad de acceso a la formación de capital humano, pero las ocupaciones se asignan por criterios extrameritocráticos -por ejemplo nepotismo o compromisos clientelares-, las políticas públicas a favor de los menos aventajados son marcadas, de antemano, por los signos del fracaso y la injusticia. La igualdad de oportunidades para acceder a puestos y ocupaciones se garantiza cuando la sociedad se arregla conforme a principios liberales; la posibilidad de equiparar las habilidades de los individuos se instala en la sociedad cuando el Estado altera esos criterios liberales y ofrece libre acceso a la educación, a la cultura y a la habilitación para el desempeño productivo y laboral.

Sin embargo, el principio de igualdad de oportunidades aplica también en sentido contrario: como limitante de la política hacia los menos aventajados. Cuando ésta se identifica -como se ha venido haciendo- con el combate a la pobreza extrema, la prevalencia de la igualdad de oportunidades conjura el uso -muy socorrido por gobiernos de origen revolucionario o de tinte populista- de instrumentos tendentes a modificar la estructura de la propiedad o de los incentivos que guían la iniciativa individual. 
Entre éstos se encuentran la reforma agraria, la contratación condicionada a la aquiescencia de los sindicatos y, en general, toda asignación de funciones que obedezca privilegiadamente a los deseos de favorecer a los más pobres, con independencia de sus habilidades y de sus esfuerzos para llevar con éxito las tareas involucradas.

Por último, la primacía del principio de ahorro justo prevé contra prácticas -generalmente identificadas con el populismoque ponen en juego la continuidad del crecimiento económico. En esencia, se trata de impedir que los recursos necesarios para mantener las tasas de expansión de la inversión se canalicen hacia el consumo, como cabe esperar de una política favorable hacia los más pobres orientada a impulsar exógenamente su capacidad de compra, en lugar de invertir en las personas que conforman ese núcleo social. La primera opción significa instituir y prolongar indefinidamente la dependencia que usualmente guardan hacia el Estado; la segunda, por el contrario, introduce claramente un principio de subsidiariedad, que por su propia naturaleza es temporal.

La anterior es una primera interpretación del principio de ahorro como condicionante del principio de diferencia. Reposa en dos supuestos: que la función de producción incorpora al capital humano como uno de los determinantes del crecimiento; y que los gastos destinados a desarrollar capacidades individuales comparten la misma estructura lógica que anima el proceso de inversión, es decir, la postergación del consumo presente que libera recursos para ser canalizados a la acumulación de activos (en este caso humanos, como la educación), que finalmente deberán arrojar rendimientos superiores al monto de recursos sacrificados. El primero es respaldado por las teorías endógenas del crecimiento; y el segundo, por la teoría del capital humano.

Sin embargo, el espíritu de la recomendación rawlsiana parece ser más restrictivo: en la medida en que la activación del principio de diferencia y la actividad de inversión física -es decir, en su sentido tradicional- compitan por los recursos, cuando el nivel de ahorro es insuficiente para garantizar una tasa aceptable de crecimiento, la política social hacia los menos aventajados debe ser sacrificada, independientemente de la forma que asuma el combate a la pobreza extrema. En la primera interpretación, los recursos que se distraen de la inversión en capital físico son, o pueden ser, compensados por la inversión en capital humano, sin 
desmedro del dinamismo económico ${ }^{1}$ en la segunda, esa reparación no es concebible porque se omiten los vínculos probables entre capital humano y crecimiento, al tiempo que se tiende a percibir el combate a la pobreza como un quehacer orientado exclusivamente hacia el consumo; una convicción muy socorrida en la época en que Rawls escribió su Teoría de la Justicia.

Desde la perspectiva rawlsiana, la restricción que sobre el principio de diferencia ejerce el correspondiente al de ahorro justo reviste un aspecto de justicia intertemporal, pero también denuncia -aunque sea veladamente- el desperdicio implícito en una política social que ponga en juego las potencialidades que el crecimiento libera, cuando se le observa como generador de oportunidades. Esto explica por qué las acciones públicas hacia los más aventajados son acotadas por el principio de ahorro, cuando los recursos asociados a esas tareas son vistos como una actividad de consumo y no como de inversión en capital humano que, a su vez, puede incidir favorablemente en el crecimiento. Cuando esto sucede, y además el ahorro necesario para mantener el ritmo de expansión económica se ve amenazado por la canalización de recursos hacia rubros propios del combate a la pobreza, se corre el riesgo de disminuir las oportunidades para el conjunto social, pero también para el grupo de pobres que se pretende beneficiar. Basta con soslayar el vínculo potencial entre formación de capital humano en los pobres extremos y el crecimiento, para que la política social compita por los recursos con la inversión, y por esta vía, se incurra en un trade off entre crecimiento y bienestar para los más desprotegidos. Cuando este fenómeno se presenta, la cuerda se rompe por lo más delgado: la política social debe ceder ante la necesidad de impulsar el crecimiento, en virtud de que sus rendimientos serían prácticamente nulos cuando el dinamismo económico se detuviera: los individuos pueden estar habilitados para aprovechar las oportunidades, pero si el crecimiento se ve afectado por la escasez de ahorro, éstas se cancelan o no crecen a un ritmo similar al de los beneficiarios de la política social. El resultado es claramente previsible: ineficacia de la acción estatal dirigida a mejorar permanentemente el bienestar de los menos aventajados.

La política de combate a la pobreza extrema del gobierno mexicano parece seguir esta segunda versión del ordenamiento de los principios de Rawls, a pesar de que la influencia del capital

${ }^{1}$ En principio, esto es así. Pero supone que ambos tipos de capital tienen el mismo efecto sobre el crecimiento. 
humano sobre el crecimiento económico se ha convertido en conocimiento no sólo disponible, sino cada vez más público. En este sentido, la política social contra la pobreza tiende ser concebida como un 'residuo' de la gestión estatal, y no como una parte sustancial de la política de desarrollo: se finca privilegiada y correctamente en la formación de capital humano, pero niega el papel que éste puede tener en el crecimiento económico cuando se dirige hacia los pobres extremos (véase el esquema III).

\section{Esquema III \\ Ubicación del combate a la pobreza}

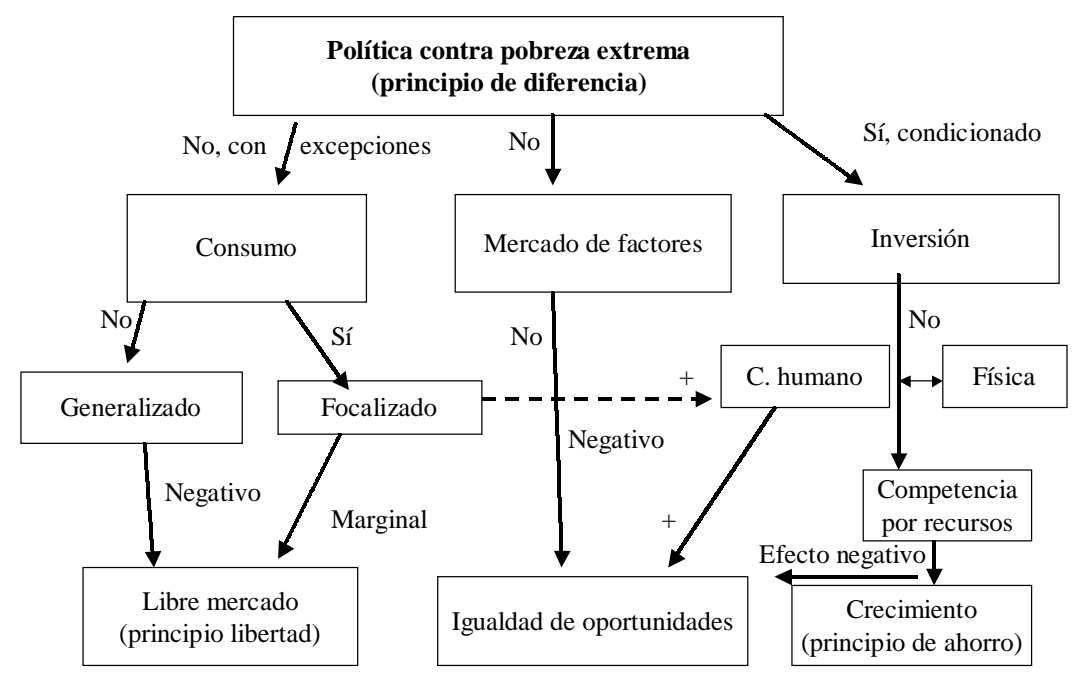

El esquema III muestra esta desconexión, pero también las restricciones que debe enfrentar el combate a la pobreza extrema cuando se adopta un modelo de desarrollo como el que rige en México desde mediados de los años ochenta. En ella se exhibe que, al seguir la interpretación de Rawls, una política orientada hacia las capacidades y -en menor medida- hacia el capital embrionario es la única que resulta compatible con el patrón de desenvolvimiento económico, en la medida en que cualquier otro derrotero altera, desde el punto de vista rawlsiano, los principios de justicia, y desde la óptica gubernamental, los pilares en los que se sostiene el funcionamiento de ese patrón. 


\section{Educación y crecimiento: la agenda pendiente}

La conclusión de que una política centrada en el desarrollo de capacidades es la única compatible con el nuevo modelo de desarrollo, marca la línea estratégica que debe seguir el combate a la pobreza extrema. Sin embargo, deja en la agenda asuntos que pueden determinar la suerte de los programas que guían esa lucha. Entre éstos, destacan dos: la capacidad del sistema educativo para suministrar las habilidades que demanda un mercado cada vez más competitivo y la absorción de los pobres a las actividades productivas. El primero se relaciona con la pertinencia y la calidad de la educación, mientras la incorporación de los pobres a la vida productiva evoca el tema del crecimiento económico.

La demanda por una educación de calidad ha sido ejercida constantemente por las más variadas fuerzas sociales y ha puesto en la mesa de discusión una de las columnas centrales en las que debe descansar una economía competitiva y una sociedad democrática (Cepal, 1992). De ella se esperan beneficios visibles -aunque a largo plazo- tanto para la capacidad productiva como para los agentes sociales que acceden a niveles superiores de educación. Bajo este marco se encuadra la política social de combate a la pobreza extrema en México: acciones como las involucradas en el Progresa (Programa de Educación, Salud y Alimentación) apuestan a fortalecer la alimentación y la salud, a fin de que los jóvenes puedan cubrir los requisitos biológicos y fisiológicos que exige el proceso de aprendizaje.

Pero también este programa ataca el flanco débil de la educación de los más pobres: la demanda. La precariedad que prevalece entre las familias que se encuentran en esa condición, obliga a complementar sus ingresos con trabajo infantil o asignando a los niños tareas de mendicidad, que terminan por separarlos de las actividades escolares. Para revertir esta propensión perversa, Progresa ofrece un estímulo monetario por cada hijo que asiste y permanece en la escuela, y que para las familias equivale al costo de oportunidad de mantener a sus miembros más jóvenes en los planteles y lejos de la calle o de la actividad laboral. De esta forma, se espera que la continuidad en la formación básica, aunada a la satisfacción de los requisitos nutricionales y sanitarios, desemboque en individuos con habilidades suficientes para incrustarse y desempañarse en las actividades productivas.

El diseño del programa parece impecable. No obstante, reposa sobre dos premisas que distan de cumplirse en el México 
actual y que requieren de reformas más amplias en la esfera educativa y en el funcionamiento económico (véase el cuadro 1).

Cuadro 1

Desempleo e instrucción en México. Tasas de desempleo abierto en áreas urbanas por nivel de instrucción

\begin{tabular}{|l|r|r|r|r|r|r|}
\cline { 2 - 7 } \multicolumn{1}{c|}{} & \multicolumn{1}{c|}{1994} & 1995 & 1996 & \multicolumn{1}{c|}{1997} & \multicolumn{1}{c|}{1998} & \multicolumn{1}{c|}{1999} \\
\cline { 2 - 7 } \multicolumn{1}{c|}{} & \multicolumn{1}{c|}{$\%$} & \multicolumn{1}{c|}{$\%$} & \multicolumn{1}{c|}{$\%$} & \multicolumn{1}{c|}{$\%$} & \multicolumn{1}{c|}{$\%$} & \multicolumn{1}{c|}{$\%$} \\
\hline Sin instrucción & 2.2 & 2.6 & 2.1 & 1.3 & 1.6 & 1 \\
\hline Primaria incompleta & 8.6 & 8.9 & 7.8 & 7 & 6.6 & 3.5 \\
\hline Primaria completa & 17.3 & 17.4 & 16.3 & 14.9 & 14.4 & 11.8 \\
\hline Secundaria & 40.9 & 40 & 39.6 & 40.1 & 37.3 & 40.7 \\
\hline $\begin{array}{l}\text { Medio superior y } \\
\text { superior }\end{array}$ & 31 & 31.1 & 34.2 & 36.7 & 40.1 & 43 \\
\hline
\end{tabular}

Fuente: INEGI, Indicadores de Empleo y Desempleo.

El cuadro 1 exhibe las tasas de desempleo por nivel de instrucción para áreas urbanas. La conclusión es que la tasa de desempleo aumenta con el nivel de instrucción, de forma invariable en el rango entre personas sin instrucción y las que cuentan con la secundaria terminada, y en todo el intervalo a partir de 1999.

El verdadero significado de estas cifras emerge cuando se las compara con la evolución que han mostrado desde 1984 las remuneraciones del trabajo calificado y del no calificado. De conformidad con Lustig (citada por World Bank, 2000), a partir de ese año los mercados laborales han tendido a premiar las calificaciones de la fuerza de trabajo y a castigar a sus integrantes que ostentan menos habilidades. En este sentido, parecería que existe una contradicción entre esta tendencia y la que apunta a una correlación positiva entre desempleo e instrucción: las remuneraciones son un indicador de la demanda laboral y pueden estar representando mayores requerimientos de fuerza de trabajo calificado; por tal razón, un alza continua sugeriría una asociación negativa entre desempleo y educación, en contra de lo que aportan las cifras anteriores.

Veamos las cosas con mayor detalle. Supongamos una economía de competencia, en la que los precios y salarios están dados para los empresarios. Si llamamos: $W$ al salario; $p$ a los precios; $L$ al volumen de empleo, y $q$ a la cantidad producida, la función de ganancias $p$ puede ser representada de la siguiente forma: 
Donde $C F$ es el costo fijo. Si se maximiza esta función, el resultado es:

$$
\begin{aligned}
& \pi=p q-(L W+C F) \\
& \frac{d q}{d l}=\frac{W}{p}
\end{aligned}
$$

La productividad marginal del trabajo es igual al salario real o, inversamente, el valor de esta productividad equivale al salario nominal del trabajador. De esta expresión podemos estimar la función de demanda de trabajo, como se aprecia en la gráfica I:

\section{Gráfica I}

Salario y productividad

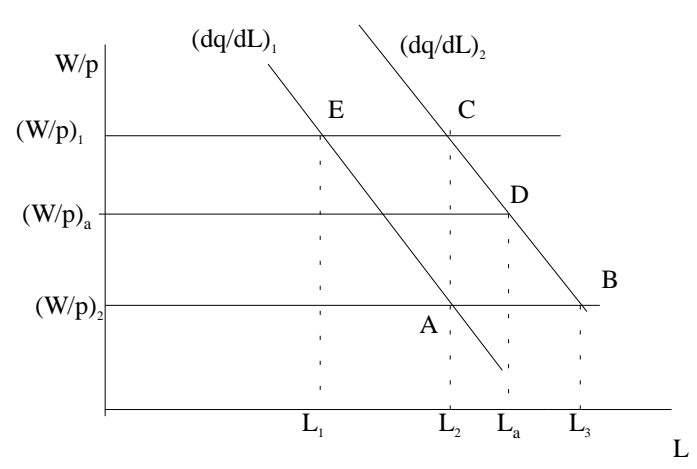

En el punto $E$, el nivel de productividad permite que al salario $W_{1}$ se absorba un volumen de empleo $L_{1}$. Si el salario baja y la función de productividad marginal se mantiene, el empleo aumenta hasta $L_{2}$. Esta trayectoria describe la función de productividad marginal como una curva de demanda de trabajo, que relaciona negativamente el nivel de empleo con las remuneraciones laborales. Si la eficiencia aumenta con mejores calificaciones de la mano de obra, la función de productividad -y por tanto, la función de demanda- aumenta mediante un desplazamiento hacia la derecha. Entonces puede suceder que el salario crezca porque se mantiene el mismo nivel de empleo (tránsito de $A$ hacia $C)$; o que ambos se vean impulsados, como lo refleja el movimiento de $A$ hacia $D$. Esto último es lo que parece que ha pasado con el trabajo calificado, mientras que el que registra menos habilidades tiende a moverse en sentido opuesto. 
Sin embargo, no hay contradicción con los datos que vinculan la instrucción formal con las tasas de desempleo: lo que revelan las dos tendencias descritas es que, a pesar de que las remuneraciones y el empleo de fuerza laboral calificadas mejoran, la educación no brinda las habilidades que el mercado demanda. Sólo así es posible compatibilizar una demanda creciente por trabajadores más habilitados con tasas de desempleo que aumentan con el nivel de educación formalizada: esas calificaciones son suministradas por otras instancias, pero no por el sistema educativo nacional.

Las consecuencias para la política de combate a la pobreza fincada en la formación de capital humano pueden ser desastrosas. En la medida en que el programa central (Progresa) se dirige a garantizar la permanencia y el aprendizaje en el sistema educativo nacional, y que éste exhibe serias fallas cuando se trata de propiciar la inserción de sus egresados en el mercado laboral, la política de reducción de la pobreza extrema corre un serio riesgo de naufragar si no se ve acompañada por una reforma del sistema educativo o, alternativamente, por una relocalización de la formación de capital humano para los más pobres en actividades que operan como generadoras de habilidades pertinentes (véase el cuadro 2).

\section{Cuadro 2}

Escenarios para lograr abatir el desempleo en México

\begin{tabular}{|c|r|r|r|r|}
\hline Periodo & $\begin{array}{c}\text { Elasticidad } \\
\text { InPIB/In } \\
\text { Empleo }\end{array}$ & $\begin{array}{c}\text { Crecimiento } \\
\text { anual de la } \\
\text { PEA }\end{array}$ & $\begin{array}{c}\text { Crecimiento } \\
\text { anual del PIB } \\
\text { necesario para } \\
\text { mantener la } \\
\text { TDA }\end{array}$ & $\begin{array}{c}\text { Crecimiento } \\
\text { anual del PIB } \\
\text { necesario para } \\
\text { eliminar el } \\
\text { desempleo }\end{array}$ \\
\hline $1989-1998$ & 0.70797 & $4.41 \%$ & $6.23 \%$ & $6.30 \%$ \\
\hline $1990-1998$ & 0.70797 & $3.97 \%$ & $5.61 \%$ & \\
\hline $1991-1998$ & 0.70797 & $3.41 \%$ & $4.82 \%$ & \\
\hline $1996-1998$ & 0.70797 & $3.90 \%$ & $5.51 \%$ & \\
\hline
\end{tabular}

Estas estimaciones parten de los siguientes datos y supuestos:

- Se tomó el último dato de la PEA (39’507,603 personas, 1998).

- Se consideró la tasa media de crecimiento de la PEA más acorde con la dinámica más reciente (3.41\%).

- Se supone que la PEA crecerá de acuerdo con su comportamiento histórico más reciente.

- Para llevar a cabo las estimaciones, se consideró la elasticidad constante resultante de una regresión doble logarítmica entre el personal

- Ocupado como variable dependiente y el PIB como variable explicativa correspondiente al periodo 1988-1998.

Fuente: Cálculos propios con base en los informes de gobierno y del INEGI. 
El crecimiento representa el siguiente escollo que la política de combate a la pobreza debe sortear. Como muestra el cuadro 2, la incorporación plena de los nuevos contingentes de la nueva fuerza de trabajo al mercado laboral exige que la economía se expanda a ritmos que superan una tasa de 5\%, mientras que la desaparición del desempleo en un lapso de diez años sólo es posible con un dinamismo equivalente al 6.3\%. Si los pobres extremos deben incorporarse a las actividades productivas para abandonar sus condiciones de penuria, el crecimiento económico debe ser tal que permita darles cabida en esas actividades, junto con los otros mexicanos que anualmente engruesan la población económicamente activa (PEA). De lo contrario, y aun bajo el supuesto que el sistema educativo cumpla satisfactoriamente con su función, el esfuerzo de combate a la pobreza se verá lamentablemente frustrado. Bajo la lógica rawlsiana, la política social estaría forjando personas con capacidad para aprovechar oportunidades, pero éstas simplemente ya no existirían.

El cuadro 3 muestra las restricciones al ahorro y a la balanza de pagos que, en distintos periodos, registra el crecimiento económico mexicano. La primera da cuenta del ritmo de expansión que la economía nacional puede alcanzar cuando el crecimiento se financia con ahorro interno:

$$
y=s \delta
$$

Donde $y$ representa la tasa de crecimiento del producto interno bruto; $s$, la propensión a ahorrar, y $d$ la relación producto-capital.

La restricción de la balanza de pagos determina la tasa máxima de crecimiento que la economía puede alcanzar, si se mantiene el equilibrio de la cuenta corriente de la balanza de pagos. Bajo el supuesto de que los términos de intercambio son constantes, esta restricción puede expresarse de la siguiente forma:

$$
y=\frac{x}{\beta}
$$

Donde $x$ representa la tasa de crecimiento de las exportaciones corrientes (bienes y servicios); $y$, la tasa de crecimiento del producto; y $\beta$ la elasticidad-ingreso de las importaciones. 


\section{Cuadro 3}

Restricciones al crecimiento del PIB, 1950-1999

\begin{tabular}{|c|r|r|r|r|}
\hline Periodo & $\begin{array}{c}\text { Restricción de } \\
\text { ahorro }\end{array}$ & \multicolumn{2}{|c|}{$\begin{array}{c}\text { Restricción de balanza de } \\
\text { pagos }\end{array}$} & PIB efectivo \\
\hline & & $\begin{array}{c}\text { Elasticidad } \\
\text { constante }\end{array}$ & $\begin{array}{c}\text { Elasticidad } \\
\text { implícita }\end{array}$ & \\
\hline $1950-1975$ & $\mathrm{nd}$ & 4.51 & 4.04 & 6.56 \\
\hline $1960-1975$ & 5.44 & $\mathrm{~ns}$ & 4.04 & 6.85 \\
\hline $1971-1975$ & 5.92 & $\mathrm{~ns}$ & 3.09 & 6.8 \\
\hline $1975-1985$ & 5.37 & 8.87 & 6.28 & 4.28 \\
\hline $1977-1981$ & 7.55 & $\mathrm{~ns}$ & 5.7 & 8.85 \\
\hline $1982-1987$ & -0.78 & $\mathrm{~ns}$ & 0.11 & -0.13 \\
\hline $1985-1999$ & 2.54 & 1.22 & 2.18 & 2.67 \\
\hline $1988-1994$ & 3.15 & $\mathrm{~ns}$ & 1.28 & 3.9 \\
\hline $1994-1995$ & -5.95 & $\mathrm{~ns}$ & -24.31 & -6.31 \\
\hline $1996-1999$ & 5.79 & $\mathrm{~ns}$ & 3.19 & 5.05 \\
\hline
\end{tabular}

Fuente: Elaboración propia con base en: INEGI, Sistema de Cuentas Nacionales de México, Presidencia de la República, informes de gobierno.

Los resultados del cuadro 3 son contundentes: mientras la restricción al ahorro permite, en términos generales, alcanzar tasas necesarias para incorporar a los nuevos miembros de la PEA, la restricción de la balanza de pagos ha tendido a recrudecer, imponiendo una tasa de crecimiento muy inferior a la que dicha incorporación reclama. La violación de esta restricción ha sido la causa de las crisis recurrentes que ha sufrido la economía nacional. Razón por la que es poco probable y poco recomendable que ésta se expanda a ritmos superiores. Pero esta prescripción deja con una gran debilidad a la política de combate a la pobreza extrema. A menos -y esto es lo importante- que la política económica de largo plazo emprenda reformas de índole estructural que relajen esta restricción.

\section{Conclusiones}

El modelo de desarrollo fincado en la exportación de manufacturas demandó no sólo una política económica liberal, sino que confinó el combate a la pobreza a adoptar una estrategia inspirada en la teoría de la justicia de John Rawls. Esta estrategia es la única que resulta compatible con el modelo de desarrollo y con la política económica concomitante, a los cuales debe permanecer subordinada. Sin embargo, las reformas se han quedado cortas, en la medida en que sin una reforma al sistema educativo que 
garantice el suministro de las habilidades que demanda el mercado, y sin una política orientada a distender las restricciones externas al crecimiento, la política social de combate a la pobreza estará destinada a naufragar en la frustración, aun cuando su diseño sea el adecuado.

\section{Bibliografía}

Cepal (1992), Educación y conocimiento. Eje de la transformación productiva con equidad, ONu, Santiago de Chile.

Fajnzylber, F. (1981), La industrialización trunca de América Latina, Editorial Imagen, México.

Kukathas, Ch. y Philip Petit (1990), Rawls. A theory of justice and its critics, Stanford University Press, Stanford, California.

Millán, H. (1998), Neoliberalismo y transición en México, El Colegio Mexiquense, Zinacantepec, México.

Poder Ejecutivo Federal (1998), Proyecto de presupuesto de egresos de la federación, México.

— (1999), Proyecto de presupuesto de egresos de la federación, México.

— (2000), Proyecto de presupuesto de egresos de la federación, México.

- (2001), Proyecto de presupuesto de egresos de la federación, México.

Rawls, J. (1995), Teoría de la justicia, FCE, México.

Sen, A. (2000), Libertad y desarrollo, Editorial Planeta, Barcelona.

World Bank (2000), Annual Report, Washington, D.C.8

Enviado: 10 de julio de 2001

Aceptado: 19 de julio de 2001 